\title{
Níveis séricos de uréia e creatinina em cães com leptospirose aguda determinada por amostras do sorogrupo Icterohaemorrhagiae
}

\author{
Blood urea nitrogen and creatinine levels in dogs with acute leptospirosis determined by \\ Icterohaemorrhagiae serogroup
}

Isabel Maria Alexandre Freire ${ }^{I}$ Renato Varges ${ }^{I}$ Walter Lilenbaum*I

\begin{abstract}
Foram testadas 120 amostras séricas de cães com títulos $(\geq 100)$ perante Icterohaemorrhagiae para a determinação dos níveis séricos de uréia e de creatinina. Os animais com títulos $\geq 800$ apresentaram dosagens de uréia bastante superiores aos valores de referência e os com títulos $\geq 200$ e $\leq 400$ apresentaram valores de uréia significativamente menores $(P<0,05)$ do que os anteriores, porém ainda acima dos valores de referência. As amostras com títulos menores que 200 apresentaram dosagens de uréia significativamente menores $(P<0,05)$ do que os observados nos outros grupos $e$ dentro dos valores de referência. No que se refere à dosagem de creatinina sérica, verificou-se que apenas os animais com títulos $\geq 800$ apresentaram dosagens acima do padrão normal. Observou-se uma clara correlação entre dano renal e a sororreatividade específica para leptospirose.

Palavras-chave: Leptospirose, cães, uréia, creatinina, Icterohaemorrhagiae.
\end{abstract}

- NOTA-

\section{ABSTRACT}

One hundred and twenty serum samples from dogs with specific titres $(\geq 100)$ against Leptospira sp. serovar Icterohaemorrhagiae for the dosage of blood urea nitrogen $(B U N)$ and creatinine levels were tested. Animals presenting titres $\geq 800$ showed BUN levels higher than reference values while samples with titres $\geq 200$ and $\leq 400$ presented $B U N$ levels significantly lower $(P<0.05)$ than the others, but still higher than the reference values. Samples presenting titres lower than 200 showed BUN dosages according to the reference values. In relation to creatinine dosage, only samples presenting titres $\geq 800$ showed dosages higher than the reference values. A correlation between renal damage and specific seroreactivity for leptospirosis was demonstrated.
Key words: $\begin{aligned} & \text { Leptospirosis, dogs, BUN, creatinine, } \\ & \text { Icterohaemorrhagiae. }\end{aligned}$

Key words: $\begin{aligned} & \text { Leptospirosis, dogs, BUN, creatinine, } \\ & \text { Icterohaemorrhagiae. }\end{aligned}$

A leptospirose, doença infecciosa e contagiosa determinada por serovares de Leptospira interrogans, afeta várias espécies de animais, além do homem (FAINE et al., 2000). Em cães, a doença é caracterizada por sinais clínicos bastante variados, manifestando-se desde uma forma aguda até as formas crônica e subclínica (HAGIWARA et al., 2004). Os serovares Icterohaemorrhagiae, Copenhageni e Canicola são os mais freqüentes em cães na região Sudeste do Brasil (LILENBAUM et al., 1997). A infecção por Icterohaemorrhagiae, que tem como reservatórios primários os roedores, determina doença aguda e severa (FAINE et al., 2000), que se caracteriza principalmente por comprometimentos renal e hepático severos (GREENE et al., 2006).

A associação dos dados sorológicos com alterações bioquímicas permite uma caracterização mais rápida do quadro clínico, facilitando tanto o diagnóstico da enfermidade quanto o prognóstico dos animais (KOGIKA et al., 1990). Dosagens de uréia e creatinina séricas têm sido relatadas (HAGIWARA et al., 2004), inclusive em animais experimentalmente infectados (NAVARRO et al., 1981). O objetivo do presente estudo foi descrever as alterações nos níveis séricos de uréia e creatinina em cães clinicamente

ILaboratório de Bacteriologia Veterinária, Departamento de Microbiologia e Parasitologia, Universidade Federal Fluminense (UFF), Niterói, RJ, Brasil. *Endereço para correspondência: Rua Hernani Mello, 101, 24210-130, Niterói, RJ, Brasil. E-mail: mipwalt@vm.uff.br. 
suspeitos de leptospirose aguda determinada pela amostra Icterohaemorrhagiae e relacionar estes achados com os títulos de anticorpos específicos.

Foram analisadas 120 amostras séricas de cães com sinais clínicos sugestivos de leptospirose aguda, caracterizada principalmente por icterícia, febre, petéquias e inapetência, provenientes da cidade do Rio de Janeiro e adjacências, no período de março a novembro de 2004. Informações sobre a gravidade do estado clínico, realização do tratamento e recuperação dos animais foram fornecidas pelo médico veterinário clínico. Todas as amostras foram testadas pelo teste de soroaglutinação microscópica com antígenos vivos, conforme recomendação da OMS (FAINE et al., 2000).

As amostras selecionadas foram encaminhadas para dosagens bioquímicas. Para tal, utilizou-se o aparelho de bioquímica automatizado (Ciba Express 550 ${ }^{\circledR}$ ) e reativos comerciais $\left(\right.$ Labtest $\left.^{\circledR}\right)$. A uréia foi determinada por método enzimático ultravioleta e a creatinina por método cinético e o processamento das amostras foi realizado de acordo com as recomendações do fabricante. As variáveis quantitativas foram analisadas através do teste de Kruskal Wallis, com auxílio do software estatístico SPSS versão 12.0 (SPSS Inc, Chicago, EUA).

Dos 120 soros que apresentaram títulos perante amostras do sorogrupo Icterohaemorrhagiae, 88 (73,3\%) apresentaram títulos $\geq 200$ e foram considerados positivos. Baseando-se nos títulos alcançados, os soros foram classificados em Grupo 1, ou fortemente reativos, com títulos $\geq 800$ (25 animais 20,8\%); Grupo 2, ou reativos, com títulos entre 200 e 400 (63 animais - 52,5\%) e Grupo 3, ou negativos com títulos <200 (32 animais - 26,7\%), conforme tabela 1 .

Os valores dos níveis séricos de uréia e de creatinina estão descritos na tabela 1. Os animais pertencentes ao Grupo 1 apresentaram dosagens de uréia variando entre 20 e $614 \mathrm{mg} \mathrm{dL}^{-1}$, com média de $167,5 \mathrm{mg} \mathrm{dL}^{-1}$. Apesar de cinco animais (20\%) apresentarem valores normais, a média é bastante superior aos valores de referência, entre $21-60 \mathrm{mg} \mathrm{dL}^{-1}$ (KANEKO et al., 1997). Já os animais do Grupo 2 apresentaram valores de uréia variando entre 12 e 336mg dL $\mathrm{m}^{-1}$, com média de 83,2mg dL $\mathrm{dL}^{-1}$. Estes valores, apesar de significativamente menores $(\mathrm{P}<0,05)$ do que os observados no Grupo 1, estão ainda acima dos valores de referência. As amostras do Grupo 3 apresentaram dosagens de uréia entre 16 e $226 \mathrm{mg} \mathrm{dL}^{-1}$, com média de $57 \mathrm{mg} \mathrm{dL}^{-1}$, também significativamente menores $(\mathrm{P}<0,05)$ do que as observadas nos Grupos 1 e 2. Neste grupo, apesar de seis animais $(18,7 \%)$ apresentarem dosagens $>60 \mathrm{mg} \mathrm{dL}^{-1}$, a média do grupo esteve de acordo com os valores de referência, portanto, dentro da normalidade.

No que se refere à dosagem de creatinina sérica, verificou-se que os animais do Grupo 1 apresentaram dosagens variando entre 0,5 e 11,7mg $\mathrm{dL}^{-1}$, com média de $2,5 \mathrm{mg} \mathrm{dL}^{-1}$. Este valor médio está acima do padrão normal, entre 0,5 e $1,5 \mathrm{mg} \mathrm{dL}^{-1}$, embora 10 animais (40\%) tenham apresentado dosagens dentro do padrão de normalidade. No Grupo 2, o valor médio foi de $1,9 \mathrm{mg} \mathrm{dL}^{-1}$, com variação entre 0,3 e $21,5 \mathrm{mg} \mathrm{dL}^{-1}$. Já no Grupo 3, a média foi de $0,9 \mathrm{mg} \mathrm{dL}^{-1}$, variando entre 0,3 e 4,0 mg dL ${ }^{-1}$. Embora a comparação entre os Grupos 1 e 2 não tenha se mostrado significativa, os valores verificados para o Grupo 3 são significativamente menores $(\mathrm{P}<0,05)$ do que os observados nos Grupos 1 e 2 .

Uma clara relação $(\mathrm{P}<0,05)$ foi observada entre os títulos de anticorpos e a dosagem de uréia e creatinina, conforme figuras 1 e 2 . Dentre os animais com títulos $\geq 200$, isto é, o somatório dos animais dos grupos 1 e 2, 73,9\% apresentavam elevação na uréia e $67 \%$ na creatinina. Já entre os animais negativos (Grupo 3), apenas 18,8\% dos animais apresentavam alteração a qualquer um dos parâmetros testados. Entretanto, alguns animais apresentaram dosagens normais de uréia e de creatinina mesmo na presença de leptospirose aguda. No Grupo 1, 20\% dos animais apresentaram uréia normal e $40 \%$, dosagens normais de creatinina. No Grupo 2, estes percentuais foram de 28,5 e 30,15\%, respectivamente. Assim sendo, considerou-se que, embora bastante freqüente, nem todos os animais reativos (títulos $\geq 200$ ) apresentaram dano renal significativo evidenciado pela elevação dos níveis de uréia e de creatinina.

Tabela 1 - Valores das dosagens de uréia e creatinina séricas de cães com leptospirose aguda determinada por amostras do sorogrupo Icterohaemorrhagiae.

\begin{tabular}{lccc}
\hline Grupos & $\mathrm{N}$ & $\begin{array}{c}\text { Uréia }\left(\mathrm{mg} \mathrm{dl}{ }^{-1}\right) \\
\text { mín-máx (média } \pm \text { desvio padrão) }\end{array}$ & $\begin{array}{c}\left.\text { Creatinina (mg dl }{ }^{-1}\right) \\
\text { mín-máx (média } \pm \text { desvio padrão) }\end{array}$ \\
\hline Grupo 1 (fortemente reativos) & 25 & $20,0-614,0(167,5 \pm 188,2)$ & $0,5-11,7(2,5 \pm 2,9)$ \\
Grupo 2 (reativos) & 63 & $12,0-336,0(83,2 \pm 88,1)$ & $0,3-21,5(1,9 \pm 3,1)$ \\
Grupo 3 (negativos) & 32 & $16,0-226,0(57,0 \pm 48,0)$ & $0,3-4,0(0,9 \pm 0,7)$ \\
\hline
\end{tabular}




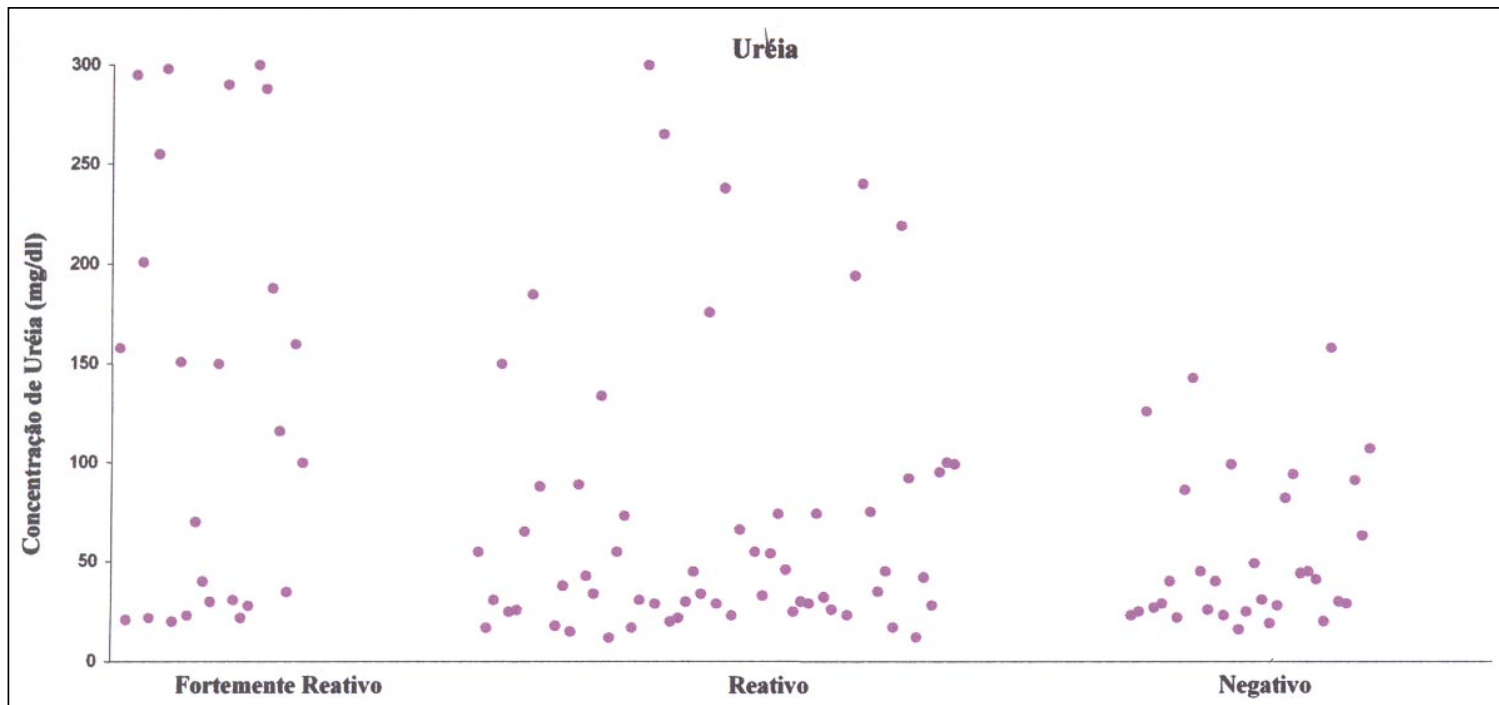

Figura 1 - Correlação entre o título de anticorpos de cães com leptospirose aguda determinada por amostras do sorogrupo Icterohaemorrhagiae e dosagem sérica de uréia $\left(\mathrm{mg} \mathrm{dL}^{-1}\right)$.

O comprometimento renal evidenciado pelo aumento nos níveis séricos de uréia e creatinina é achado freqüente nos casos de leptospirose canina aguda (LILENBAUM et al., 1997; HAGIWARA et al., 2004). A uréia e a creatinina são amplamente utilizadas como indicadores de filtração glomerular. A uréia é sintetizada no fígado a partir do catabolismo protéico e a creatinina é originada a partir da creatina muscular. Após a filtração glomerular, ambas são excretadas na urina. Considera-se que a creatinina sofre menor influência de fatores extra-renais e, portanto, seria um indicador mais fidedigno da taxa de filtração glomerular. Acredita-se que o quadro de azotemia observado nos animais reativos teria ocorrido principalmente em decorrência de redução da perfusão renal por lesões isquêmicas no parênquima do órgão e diminuição da taxa de filtração glomerular associadas à destruição das células do epitélio renal por toxinas e componentes de membrana das leptospiras (GREENE et al., 2006).

Conclui-se que existe uma clara correlação entre dano renal, caracterizado no presente estudo por elevação dos níveis séricos de uréia e de creatinina,

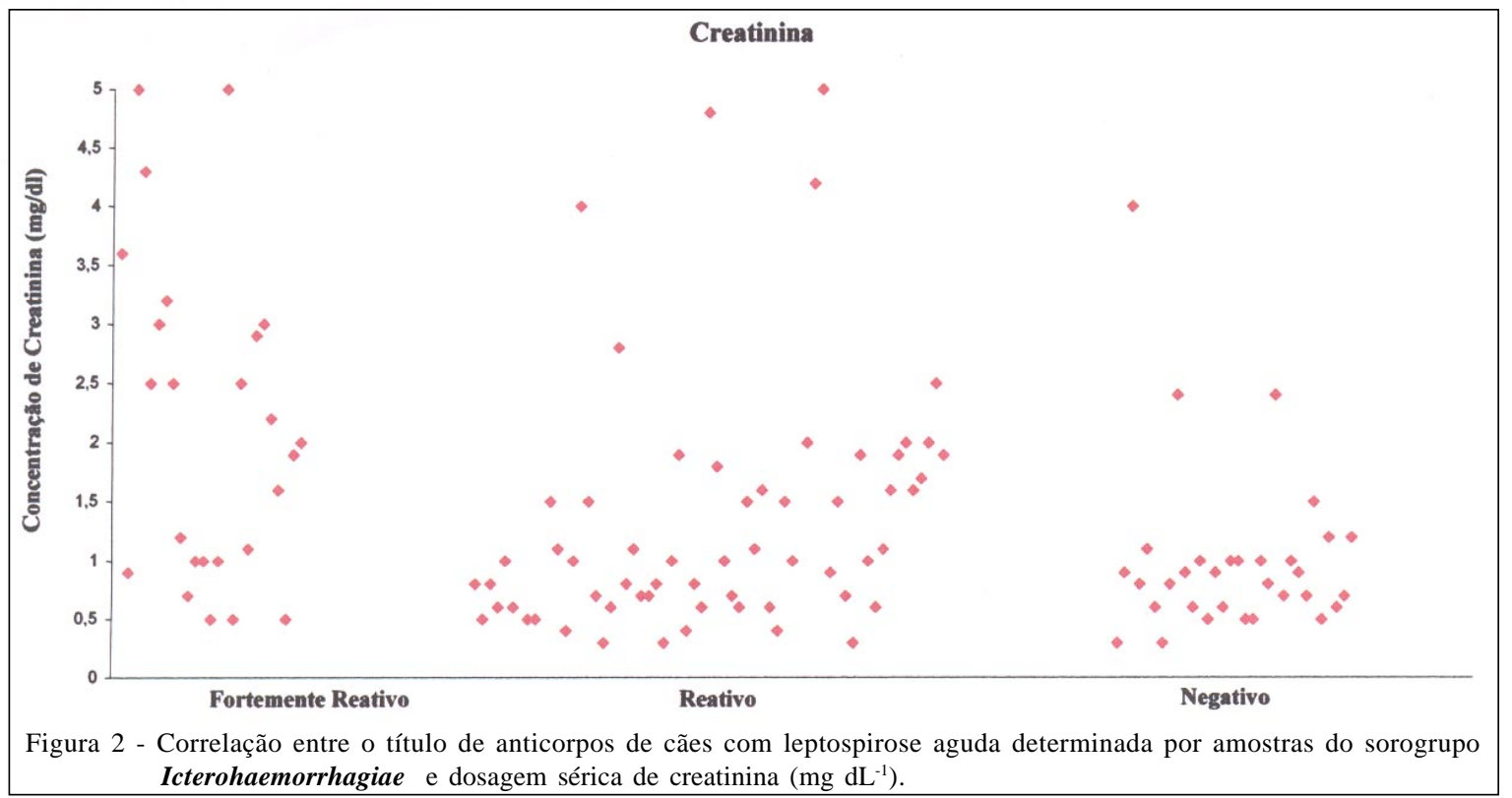

Ciência Rural, v.38, n.4, jul, 2008. 
com a sororreatividade específica para leptospirose, em animais acometidos de infecção por amostras do sorogrupo Icterohaemorrhagiae.

\section{REFERÊNCIAS}

FAINE, S. et al. Leptospira and Leptospirosis. Austrália: Medsci, 2000. 272p.

GREENE, C.E. et al. Infectious diseases of the dog and cat. Athens: Saunders, 2006. 934p.

HAGIWARA, M.K.et al. Leptospirose canina. Vet News, v.11, p.7-8, 2004.
KANEKO, J.J. et al. Clinical chemistry of domestic animals. EUA : Academic, 1997. 932p.

KOGIKA, M.M. et al. Alterações bioquímicas na leptospirose canina. Brazilian Journal of Veterinary Research and Animal Science, v.27, p.177-182, 1990.

LILENBAUM, W. et al. Dosagem de uréia sanguínea em cães com leptospirose. Revista Brasileira de Medicina Veterinária, v.19, p.233-237, 1997.

NAVARRO, C.E.K. et al. Serum biochemical changes in dogs with experimental Leptospira Interrogans serovar Icterohaemorrhagiae infection. American Journal of Veterinary Research, v.42, p.1125-1129, 1981. 